\title{
Dynamic Structural Changes in Economic Growth Determinants, Industry Change and Economic Transformation
}

\author{
Yaling Li \\ School of Business and Tourism Management, Yunnan University, Kunming, Yunnan, China
}

\begin{abstract}
This study investigates the transformation in economic growth based on the unified growth theory, using a sample of cross-sectional data over the period 2003-2018. The results show that physical capital, labor, and human capital of sample country have significant effects on economic growth measured by per capita gross domestic product, especially the impact on the growth of industrial industries; however, their contribution to economic growth has changed over time. Human capital has become the primary driving force in economic growth, the effect of physical capital cannot be ignored, and the role of labor has taken a back seat. The growth rate of total factor productivity improves economic growth, but its effect on growth has weakened since 2009, suggesting that the sample country is transforming from a post-Malthusian growth stage to a modern economic growth stage. Policy implications of the findings are discussed.
\end{abstract}

Keywords: Demographic transition, economic transformation, modern manufacturing, investment in human capital, total factor productivity, unified growth theory

\section{Introduction}

Economic transformation is an inevitable process that each country undergoes in the course of economic development. Historical experience tells us that both developed countries and newly industrialized countries have achieved sustained and rapid growth through economic transformation and upgrading. Achieving long-term and sustainable economic growth is one question that each country has to face as it passes from one stage of economic growth to the next. This paper explores the transformation of China in its economic growth. In the past 40 years of reform and opening up, China has achieved a great deal of economic development. However, China's development is still not comprehensive and balanced. Because the traditional demographic dividend has disappeared and labor costs have increased, the country no longer has a comparative advantage in low labor costs. If the country promotes exports dominated by traditional labor-intensive industries, it can easily have stagnant economic growth because of a loss in growth momentum. In this context, the transformation of the structure of growth into one based on investment in human capital, technological innovation, and institutional innovation is a critical issue in China's future sustainable economic development.

However, the process of economic development common involves going through different economic growth stages. Hence, achieving long-term and sustainable economic growth is a critical question that each country faces as it grows. Several studies explore the transformation process between different stages of human social development by using economic growth theory, while clarifying the demographic transformation and the great divergence that accompanies endogenous transformation of the economy. For example, Galor and Weil (2000) fuseed Malthusian theory with modern growth theory to create a unified growth theory framework, which suggests that five factors influence economic growth. They are labor flowing from a low-productivity sector to a high-productivity sector, a demographic dividend, capital investment, investment in human capital, and the working population as a share of the total population.

Modernization of the economy comprises three stages of growth: the first is dominated by agriculture, the second by modern manufacturing and services, and the third by human capital. Long-term economic growth consists of the transition from the first stage to second and then from the second to the third, which we call economic transformation in this paper. The main drivers of economic growth vary across the different stages. Of course, for

ISSN: 0010-8189 
historical reasons, the time and length of the economic transformation varies across different countries and regions, and the stages may overlap. In the past 40 years, rapid economic growth in China benefited from large-scale physical capital investment and the low cost of abundant labor, and the contribution to GDP of labor has fallen. But now, with investment efficiency declining, the demographic dividend gradually disappearing, and export growth falling, economic growth is slowing down. Based on the unified growth theory, the five factors mentioned above are present in China. This suggests that the Chinese economy is in the midst of a transition from one growth stage to another. Therefore, the unified growth theory is suitable to use in exploring long-term sustained growth. However, the existing literature lacks empirical evidence on this process. In addition, the complex Chinese economy has large regional economic disparities. Hence, this paper examines whether China is in the process of economic transformation, and, if so, what factors are driving it.

To address these questions, we use a cross section of data on 30 provinces and cities in China over the period 2003-2018 to test empirically the relationship between the driving factors behind changes in economic growth and economic transformation in the country. Based on the Cobb-Douglas production function, this paper constructs a model of the relationship between physical capital, labor, human capital, and economic growth. Compared to neoclassical growth model, this model considers long-term economic growth and uses Romer's new economic growth theory to distinguish human capital from Solow's surplus as an endogenous variable. This paper contributes to the literature by presenting empirical evidence on the stages of economic transformation in China and then offering policy recommendations to attain long-term sustained economic growth.

\section{Literature Review}

The study on the relationship between the main dynamic factors change of economic growth and the economic transformation, as interpreted by unified growth theory, is still in its infancy. By reviewing the relevant literature, we aim to identify their logical relationship to establish the theoretical framework of this paper.

\subsection{Unified Growth Theory: Division of Economic Growth Stages and the Characteristics of Each Stage}

According to Galor (2008), the concept of being "unified" has two meanings. The first refers to the unity of a macroeconomic model with a microeconomic foundation. The second is that the different stages in long-term economic development are unified in a mode ${ }^{[1]}$. And because of these two characteristics, every kind of economic growth theory before unified growth theory has different defects. The unified growth theory holds that the development of human society is divided into three stages: the Malthusian growth period, the post-Malthusian growth period, and the modern economic growth period. The difference between the first two periods lies mainly in the speed of technological progress. Technological progress was slow in the Malthusian growth period but rapid in post-Malthusian growth period. The main difference between the latter two periods is the speed of population growth. Population growth was rapid in post-Malthusian growth period, while it was slow and even appeared to be negative in the modern economic growth period.

Transformation between different growth periods is a gradual and slow process. The process can be summed up in a complex dynamic system in which technology progress, human capital accumulation, and personal factors, such as the optimal reproductive choice, are included. Each period has different characteristics. The Malthusian economic growth period has the following characteristic: technical progress and resource expansion make the population grow, which further affects technological progress. For a long time, per capita income was low, and its average value fluctuated around the level of survival. The core assumption of this period that the limited land resource is one of the important input factors, so the marginal productivity of labor decreases.

The typical feature of economic development in post-Malthusian growth period is that per capita income rises, which has a positive effect on population growth; technological progress speeds up, and output has a higher growth rate than population. The core assumption of this period is that human capital and its influence on population transformation and technological progress is the important reason that the economy moves from the post-Malthusian growth period to the modern economic growth period. The typical features of economic

ISSN: 0010-8189 
development in the modern economic growth stage are as follows. Technological progress accelerates. The level of human capital level rises. Per capita income continues to grow. The rate of population growth declines. The core assumption of this period is that both technological progress and its effect on the demand for human capital and the decline in the population growth rate are important reasons for moving from stagnation to a sustained growth period. Moreover, human capital accumulation and technological progress interact.

\subsection{Changes in the Dynamic Factors of Economic Growth and Transformation in the Economic Growth Stage}

What are the main forces of the transformation in economic growth? Scholars who study the unified growth theory have different answers to this question. They mainly explain the transformation in economic growth through stages in human capital accumulation, technological progress, and demographic and institutions transition.

\subsubsection{Technical Progress and Economic Transformation}

Galor (2000) and Hansen and Prescott (2002) argue that both endogenous technical progress and the exogenous technology impact are important reasons for the economy to move from stagnation to sustained growth $1^{[2,3]}$. Jones (2001) believes that two factors play a vital role in the transition of economic development from the Malthusian trap to sustained growth. The first one is that the number of people who exchange ideas positively promotes technical progress. The second is that the continuing improvement of various institutions promotes innovation $\mathrm{I}^{[4]}$.

\subsubsection{Human Capital and Economic Transformation}

Tamura (2002) uses human capital accumulation to explain endogenous human transformation from an agricultural society to an industrial society ${ }^{[5]}$. Lagerlof (2003) points out that stable human capital accumulation moves the economy from a Malthusian growth period to a post-Malthusian growth period and then to a modern stage of sustained economic growth ${ }^{[6]}$. Galor and Moav (2004) find that, at the early stage of economic development, because the economy has less physical capital, human capital had a lower rate of return than physical capital. Hence, economic growth was driven mainly by physical capital ${ }^{[7]}$. Therefore, as the economy continued to develop, the physical capital accumulation in the economy increases, which raises the rate of return on human capital and in turn increases investment in human capital. The increase in human capital becomes important for promoting economic growth.

\subsubsection{Changes in Population Structure and Economic Transformation}

Doepke (2004) suggests that changes in the population structure affect economic development in the following ways. First, the higher the population growth rate is, the lower the physical capital stock per capita, therefore, per capita income is lower. Second, a higher birthrate is usually accompanied by a lower level of education and human capital. Third, population growth affects the entire economy by influencing the age structure of the population and the amount of labor ${ }^{[8]}$. Boucekkine et al. (2003) build an iterative intertemporal model. Their quantitative research showed that demographic transition affects economic growth by affecting the motivation for human capital accumulation and investment in education ${ }^{[9]}$.

\subsubsection{Institution and Economic Transformation}

Based on the unified growth theory, in addition to the constraints of economic and demographic variables, institutional variables should also be considered. Galor (2010) believes that the system of land ownership influences economic transformation by affecting the level of human capital ${ }^{[10]}$. Of course, there are major differences in the timing of technological progress, human capital formation, and demographic transition resulting from an equal distribution of land ownership.

In sum, technological progress, human capital accumulation, demographic and institutions transition are closely related to economic transformation. All of them are endogenous and depend on the economic system. They play a major role in promoting economic growth at different stages of economic development, and changes in them contribute to the leap from one economic growth stage to the next. But the main motive force of economic growth is different in different stages of economic development.

ISSN: 0010-8189 


\section{Model and Data}

By sorting out the theoretical research and international experience of growth dynamic transformation in different stages proposed by the unified growth theory, this paper, from the perspective of supply-side considerations, uses the production function to investigate the dynamic transformation of China's economic growth.

\subsection{The Model}

The Cobb-Douglas (C-D) production function has good characteristics in terms of mathematical statistics. This function becomes a linear equation by taking the logarithm. Parameter estimation is more convenient than other algebraic equations. In the technical and economic analysis, because of the data characteristics, the conclusion from calculation analysis is more accurate. As a result, it is widely used. Based on the theory stated in the literature review, this paper builds a dynamic model of the relationship between factor inputs and economic growth in terms of a C-D production function. The factor include physical capital, labor and human capital.The model is as follows: AYit= AitKit $\alpha$ Lit $\beta$ tHit $\psi t$

where AY is the per capita GDP, A is the total factor productivity, a comprehensive index that is characterized by technological progress and institutional innovation (Jorgenson, 2001), $\mathrm{K}$ is physical capital, $\mathrm{L}$ is labor, and $\mathrm{H}$ is human capital. $\alpha, \beta$, and $\psi$ are estimated parameters, representing the output elasticity coefficient of three independent variables: physical capital, labor, and human capital.

$$
\alpha=\frac{\Delta A Y / A Y}{\Delta K / K}, \beta=\frac{\Delta A Y / A Y}{\Delta L / L}, \Psi=\frac{\Delta A Y / A Y}{\Delta H / H}
$$

They reflect each factor's relative contribution to economic growth, namely, its pull effect on economic growth. Output elasticity multiplied by the growth rate of the factors is the absolute contribution of the factors. The value of $\mathrm{i}$ is $1-30$, representing 30 provinces and cities in China. $\mathrm{t}$ is the time (representing different years).

After taking the logarithm of both sides in equation (1), we obtain a linear model as follows:

$\ln \mathrm{AYit}=\mathrm{Cit}+\alpha \mathrm{t} \ln \mathrm{Kit}+\beta \mathrm{t} \operatorname{lnLit}+\psi \mathrm{t} \ln \mathrm{Hit}$

In this paper, equation (2) does not represent panel data, but cross-section data. Because we want to estimate the output elasticity of each factor in each year from 2003 to 2018, we use t to represent different years. The parameters of each year in the model are different.Cit is the intercept term, which means the growth rate of A. The $\log$ of $\mathrm{K}(\operatorname{lnK})$ is the growth rate of $\mathrm{K}$; the $\log$ of $\mathrm{L}(\operatorname{lnL})$ is the growth rate of $\mathrm{L}$; and the $\log$ of $\mathrm{H}(\operatorname{lnH})$ is the growth rate of H. Each factor's contribution to economic growth not only depends on the output elasticity coefficient but also is influenced by the factor's growth rate. Therefore, the relative contribution of the factors can better reflect the dynamic strength of the factor's influence on economic growth, rather than the absolute contribution. In this paper, the relative degree of contribution, namely, the output elasticity coefficient of factors, is used to analyze the dynamic effect of factors on economic growth.

\subsection{Description of Measures and Data}

Data from 30 provinces and cities in China from 2003 to 2018 were used and then they are added up cross-sectional data on the eastern, central, and western regions based on the area of China's administrative divisions. Tibet was excluded from the econometric model because its data is often missing. Hong Kong, Macau, and Taiwan are excluded because of their different systems and different statistical approaches. The sources of our data are explained next.

\subsubsection{Dependent Variable (AY)}

We use real per capita GDP to measure economic growth after using an implicit price deflator of per capita GDP to eliminate the influence of price factors. The base year is 2003. The data come from the China Statistical Yearbook 
from 2004 to 2019.

\subsubsection{Explanatory Variables}

Physical capital (K). Goldsmith perpetual inventory method is applied to calculate the stock of physical capital using the following equation: $\mathrm{Kt}=\mathrm{Kt}-1(1-\theta)+\mathrm{It} / \mathrm{Pt}$

where $\mathrm{K}$ is the capital stock, $\mathrm{t}$ is the year, $\theta$ is the depreciation rate of capital, $\mathrm{I}_{\mathrm{t}}$ is investment in fixed assets in the year $t$, it is the nominal variable calculated using the current price, and $P_{t}$ is the price index of investment in fixed assets in the year $t$. The depreciation rate, that is, $\theta=0.055$, comes from Wang (2010). Fixed asset investment $I_{t}$, and the price index of investment in fixed assets $\mathrm{P}_{\mathrm{t}}$ come from the New China 60-Year Statistical Data Compilation and the China Statistical Yearbook from 2004 to 2019, and 1990 is the base year. The physical capital stock in the three regions from 2003 to 2019 is calculated using equation (3) based on provincial data calculated by Zhang (2004).

Labor (L). We assume that labor intensity and labor efficiency are homogeneous, and so in this paper the level of employment is used as labor input. To obtain the panel data on the eastern, central, and western regions, we use aggregate employment in 30 provinces, municipalities, and autonomous regions from 2003 to 2018 in the China Statistical Yearbook and in local statistical yearbooks.

Human capital (H). As education is the most important method of human capital formation, the education level is used as a variable to measure human capital stock. The common methods for measuring education-based human capital relate to the cost of education, future earnings, and years of education. The "average years of education" is generally regarded as the most appropriate way of measuring education-based human capital.

We also use this measurement to calculate the average years of education of the population age 15 and above, to reflect the human capital stock. In China's education system, the average years of education of those who have a college degree or above is 16 , a high school education is 12 , a junior high school education is 9 , primary school education is 6 , and for those who are illiterate and semiliterate, it is zero. We calculate it using the following equation:

$$
\mathbf{H}=\frac{\sum_{\mathbf{i}=\mathbf{n}}^{\mathbf{n}} \mathbf{P}_{\mathbf{i}} \mathbf{h}_{\mathbf{i}}}{\mathbf{P}}
$$

Equation (4) is commonly used for calculating the average stock of human capital in education. Although it is not perfect, it is still a reasonable method compared to other methods. $\mathrm{H}$ represents the average number of years of education among those age 15 and above; i represents the level of education; $h_{i}$ represents the average number of years of education at level i; $\mathrm{P}_{\mathrm{i}}$ represents the population at hierarchical level of education $\mathrm{i}$; and $\mathrm{P}$ represents the total population at different levels of education in a certain region among those age 15 and above.

\section{Empirical Results}

\subsection{Descriptive Statistics of Variables}

Descriptive statistics of the variables are shown in Table 1.

Table 1 Descriptive statistics of the variables $(\mathrm{N}=420)$

\begin{tabular}{lcccc}
\hline Variable & AY & K & L & H \\
(unit) & $($ RMB 10,000) & (RMB 10 trillion) & (100 million) & (year) \\
\hline
\end{tabular}

ISSN: 0010-8189 


\begin{tabular}{lcccc}
\hline Mean & $27,549.35$ & $53,799.43$ & $2,570.09$ & 9.42 \\
Median & $22,564.33$ & $31,523.30$ & $2,076.90$ & 9.28 \\
Max & $104,239.09$ & $358,359.72$ & $6,809.60$ & 13.58 \\
Min & $3,685.63$ & $1,259.27$ & 289.80 & 6.35 \\
& & & & \\
Std. Dev. & $16,767.60$ & $58,711.17$ & $1,705.73$ & 1.24 \\
Cross section & 30 & 30 & 30 & 30 \\
& & & & \\
\hline
\end{tabular}

The maximum value of AY is for Shanghai in 2018, and the minimum value is for Guizhou in 2003. The maximum values of $\mathrm{K}$ and $\mathrm{L}$ are the data for Shandong and Henan in 2018 and 2016, and both minimum values are for Qinghai in 2003. The maximum value of $\mathrm{H}$ is for Beijing in 2018, and the minimum value is for Yunnan in 2003. According to the data, economic development in China from 2003 to 2018 has two characteristics. First, the economy has grown rapidly, by $9.25 \%$ a year for 16 years. Second, regional economic disparities are large, and the gaps have narrowed over time. For example, the proportion of GDP in eastern, central, and western China was $60.00 \%, 22.93 \%$, and $17.06 \%$, respectively, in 2003 and was $52.50 \%, 21.00 \%$, and $20.10 \%$ in 2018. In 2003, the highest per capita GDP was 10.28 times that of the lowest, while in 2018, the highest per capita GDP was 4.94 times that of the lowest. Moreover, the regional differences in factor inputs are also obvious.

\subsection{Regression Methods}

Because a causal relationship is found between each independent variable and the dependent variable, we use equation (2) to analyze the influence of each independent variable on the dependent variable.As the key focus of this paper is the transformation in the economic growth stage in China driven by changes in growth momentum factors, the change rules of the momentum factor are mainly measured by comparing the change in the output elasticity of factors. In the logarithmic model, the parameter of the factors is output elasticity. The parameters in the model are fixed. Whether we use time-series data or panel data cannot achieve the goal of this study. Therefore, this paper adopts the cross-section model of each year to estimate the output elasticity of each input factor over the period 2003-2018.

To compare the gap between regions and determine the change rules of the output elasticity of factors each year, we used sample data from 30 provinces and cities in China to calculate the regression equations for each year from 2003 to 2018. Considering that the cross-sectional data have heteroskedasticity because of the large regional differences, which makes the parameter estimation invalid, we consider using the weighted least squares (WLS) method for estimation. When the variance covariance matrix is known and only heteroscedasticity exists, the WLS estimator used is GLS and FGLS. In a multiple function regression, the stepwise least squares (STEPLS) regression method is used to eliminate multicollinearity.

First, we perform an ordinary least squares regression on the equations for each year of the model. Based on the Durbin-Watson (DW) results, the model has no autocorrelation. Hence, we can use WLS to eliminate heteroskedasticity. Using the Glejser test method, the variance in the vibration term is proportional to the square of the explanatory variable. Therefore, we use the reciprocal of the residual sequence squared as the weighted sequence $\omega$ i. Then, using the WLS method, both sides of the original model should be multiplied by the relevant weight, and STEPLS is used to estimate the model. The regression results are shown in Table 2.

Table 2 The regression results

\begin{tabular}{llllll}
\hline Samples & Regression results and t-Statistic & $\bar{R}^{2}$ & $\mathrm{~F}$ & $\mathrm{DW}$ & $\mathrm{nR}^{2}$ \\
\hline
\end{tabular}

ISSN: 0010-8189 


\begin{tabular}{|c|c|c|c|c|c|}
\hline 2003 & $\begin{aligned} \mathrm{LnAY}= & 3.76+0.39 \mathrm{LnK}-0.28 \mathrm{LnL}+1.87 \mathrm{LnH} \\
& \left(15.45^{*}\right)\left(6.42^{*}\right)\left(-11.28^{*}\right)\left(7.50^{*}\right)\end{aligned}$ & 0.91 & 179.08 & 2.19 & 7.02 \\
\hline 2004 & $\begin{aligned} \operatorname{LnAY} & =3.45+0.63 \mathrm{LnK}-0.42 \mathrm{LnL}+1.61 \mathrm{LnH} \\
& \left(24.65^{*}\right)(19.32 *)(-60.97 *)(22.92 *)\end{aligned}$ & 0.97 & 7357.61 & 1.81 & 10.17 \\
\hline 2005 & $\begin{aligned} \mathrm{Ln} A Y & =3.84+0.69 \mathrm{LnK}-0.46 \mathrm{LnL}+1.26 \mathrm{LnH} \\
& \left(15.46^{*}\right)(14.04 *)\left(-14.21^{*}\right)\left(11.21^{*}\right)\end{aligned}$ & 0.95 & 241.74 & 1.67 & 11.31 \\
\hline 2006 & $\begin{aligned} \operatorname{Ln} A Y= & 3.80+0.67 \mathrm{LnK}-0.46 \mathrm{LnL}+1.37 \mathrm{LnH} \\
& \left(4.00^{*}\right)\left(4.66^{*}\right)\left(-3.90^{*}\right)\left(2.43^{* *}\right)\end{aligned}$ & 0.84 & 48.67 & 1.67 & 9.89 \\
\hline 2007 & $\begin{aligned} \operatorname{LnAY}= & 3.92+0.79 \mathrm{LnK}-0.58 \mathrm{LnL}+1.18 \mathrm{LnH} \\
& \left(63.48^{*}\right)(39.61 *)\left(-40.98^{*}\right)\left(106.59^{*}\right)\end{aligned}$ & 0.97 & 18340.1 & 1.92 & 7.90 \\
\hline 2008 & $\begin{aligned} \operatorname{Ln} A Y= & 3.64+0.75 \mathrm{LnK}-0.56 \mathrm{LnL}+1.36 \mathrm{LnH} \\
& \left(3.69^{*}\right)\left(5.28^{*}\right)\left(-4.39^{*}\right)\left(2.41^{* *}\right)\end{aligned}$ & 0.84 & 49.76 & 1.69 & 10.34 \\
\hline 2009 & $\begin{aligned} \operatorname{Ln} A Y & =3.26+0.76 \operatorname{LnK}-0.56 \operatorname{LnL}+1.51 \mathrm{LnH} \\
& (24.59 *)(42.52 *)\left(-57.12^{*}\right)(68.72 *)\end{aligned}$ & 0.98 & 10240.9 & 2.03 & 7.07 \\
\hline 2010 & $\begin{aligned} \operatorname{LnAY} & =2.42+0.70 \mathrm{LnK}-0.52 \mathrm{LnL}+1.96 \mathrm{LnH} \\
& \left(31.34^{*}\right)\left(53.77^{*}\right)\left(-66.71^{*}\right)\left(92.61^{*}\right)\end{aligned}$ & 0.97 & 48591.6 & 2.25 & 0.96 \\
\hline 2011 & $\begin{aligned} \mathrm{LnAY}= & 2.00+0.76 \mathrm{LnK}-0.57 \mathrm{LnL}+2.01 \mathrm{LnH} \\
& \left(1.82^{* * *}\right)\left(5.66^{*}\right)(-4.60 *)(3.60 *)\end{aligned}$ & 0.82 & 46.43 & 1.96 & 10.81 \\
\hline 2012 & $\begin{aligned} \mathrm{Ln} A \mathrm{Y}= & 0.20+0.84 \mathrm{LnK}-0.55 \mathrm{LnL}+2.28 \mathrm{LnH} \\
& \left(0.26^{*}\right)\left(13.79^{*}\right)\left(-8.54^{*}\right)\left(5.61^{*}\right)\end{aligned}$ & 0.96 & 395.58 & 1.68 & 10.73 \\
\hline 2013 & $\begin{aligned} \operatorname{LnAY}= & 0.80+0.84 \mathrm{LnK}-0.65 \mathrm{LnL}+2.33 \mathrm{LnH} \\
& \left(2.03^{* *}\right)\left(22.39^{*}\right)\left(-22.68^{*}\right)\left(9.59^{*}\right)\end{aligned}$ & 0.97 & 449.29 & 1.90 & 0.29 \\
\hline 2014 & $\begin{aligned} \operatorname{LnAY}= & 1.04+0.76 \mathrm{LnK}-0.59 \mathrm{LnL}+2.37 \mathrm{LnH} \\
& \left(3.00^{*}\right)\left(20.89^{*}\right)\left(-20.18^{*}\right)\left(10.48^{*}\right)\end{aligned}$ & 0.97 & 2307.26 & 1.85 & 11.31 \\
\hline 2015 & $\begin{aligned} \mathrm{LnAY}= & 1.03+0.34 \mathrm{LnK}-0.22 \mathrm{LnL}+3.16 \mathrm{LnH} \\
& \left(3.03^{*}\right)\left(22.68^{*}\right)(-9.58)\left(27.03^{*}\right)\end{aligned}$ & 0.96 & 5713.37 & 1.77 & 4.36 \\
\hline 2016 & $\begin{aligned} \operatorname{LnAY}= & 1.01+0.24 \mathrm{LnK}-0.12 \mathrm{LnL}+3.32 \mathrm{LnH} \\
& \left(1.96^{* * *}\right)\left(5.16^{*}\right)\left(-2.43^{* *}\right)\left(13.64^{*}\right)\end{aligned}$ & 0.97 & 631.19 & 1.91 & 4.51 \\
\hline 2017 & $\begin{array}{c}\mathrm{LnY}=0.24+0.18 \mathrm{LnK}-0.03 \mathrm{LnL}+3.67 \mathrm{LnH} \\
(0.18)(1.66)(-0.35)\left(7.45^{*}\right)\end{array}$ & 0.69 & 21.99 & 2.35 & 8.23 \\
\hline 2018 & $\begin{array}{c}\mathrm{LnY}=0.18+0.20 \mathrm{LnK}-0.04 \mathrm{LnL}+3.63 \mathrm{LnH} \\
(0.14)(1.96)(-0.41)(8.02 *)\end{array}$ & 0.71 & 24.58 & 2.00 & 8.08 \\
\hline
\end{tabular}

Notes: The values in parentheses are t-statistics. $\mathrm{nR}^{2}$ are White test statistics (subject to chi-square distribution). $*$ represents a significance level of $1 \%$; ** represents a significance level of 5\%; *** represents a significance level of $10 \%$.

The White test method is used to determine whether any heteroskedasticity remains at a significance level of $1 \%$. Because $\mathrm{nR}^{2}<\chi_{0.01}^{2}(3)=11.34$ in the auxiliary regression model of corresponding residual squares in each year, heteroskedasticity has been eliminated in each regression equation.

The cross-sectional data for 2003, 2006, 2008, 2014, 2017, and 2018 did not have any heteroskedasticity, so the results were obtained directly by the STEPLS regression, however, the rest of the annual data showed heteroskedasticity. Therefore, the results were obtained by the STEPLS regression after the weighted procedure was performed.

\subsection{Analysis of Regression Results}

The empirical test shows that the goodness of fit of the regression equations for 16 years is relatively good, and all

ISSN: 0010-8189

(C) CONVERTER 2020 
of them passed the t test, $\mathrm{F}$ test, autocorrelation test, and White test at a significance level of 5\%. The regression results are given as follows.

\subsubsection{The Relationship between Independent Variables and Dependent Variables}

First, a positive link exists between the growth rate of physical capital, human capital, and regional economic development in China. The coefficient $\alpha$ of $\ln \mathrm{K}$ is the output elasticity coefficient of physical capital, and it represents the relative contribution of physical capital $\mathrm{K}$ to per capita output (AY). The coefficient $\psi$ of $\operatorname{lnH}$ is the output elasticity coefficient of human capital, and it represents the relative contribution of human capital $\mathrm{H}$ to per capita output (AY).The consistency of 16 annual regression results is good, which indicates that the per capita output is also higher in regions with high physical capital and human capital, showing a strong positive link between the two variables. However, the value of $\alpha$ was less than 1 in all 16 years, which indicates that the growth rate of per capita output was lower than that of physical capital input, although per capita output also increased with the growth of physical capital input. Before 2013, the value of $\alpha$ increased slowly, but after 2013, the value of $\alpha$ began to decrease. This indicates that the rate of return on investment of physical capital has declined since 2013.Nevertheless, the value of $\psi$ has been greater than 1 for 16 years, which indicates that the growth rate of per capita output was greater than that of human capital input. Before 2007, the value of $\psi$ decreased, but after 2007, the value of $\psi$ began to increase. This indicates that the rate of return on investment of human capital has begun to go up since 2007.

Second, however, we find a significant negative relationship between the growth rate of labor and regional economic development (the growth rate of AY). The coefficient $\beta$ of $\ln L$ is the output elasticity coefficient of labor, and it represents the relative contribution of labor to per capita output (AY). $\beta$ is negative, which indicates that as the growth rate of labor input increased, the growth rate of per capita output decreased. The result shows that, at this stage, compared with other factors such as physical capital, labor input was high, and labor input has begun to have diminishing marginal returns. Diminishing marginal returns on labor input indicates that the large amount of labor does not mean that the region produces more per capita output, which is related to labor productivity. In China, some underdeveloped areas are densely populated and have a large amount of labor, but the total output created is limited, which results in low per capita GDP. For example, in 2003, 2010, 2016, and 2018, Tianjin, Beijing, and Shanghai and some provinces have a small labor force but high total output, whereas in Henan, Anhui, Hunan, and other provinces, the labor force is larger, but their total output is smaller.

In 2016, for example, the labor force in Tianjin totals 90.24 million, but the per capita GDP is as high as RMB902.178 million, whereas the labor force in Henan is 68.96 million, but the per capita GDP is only RMB292.917 million (see Figure 1). This means that labor is a necessary condition for output but not a necessary condition for greater output because of the law of diminishing marginal returns.

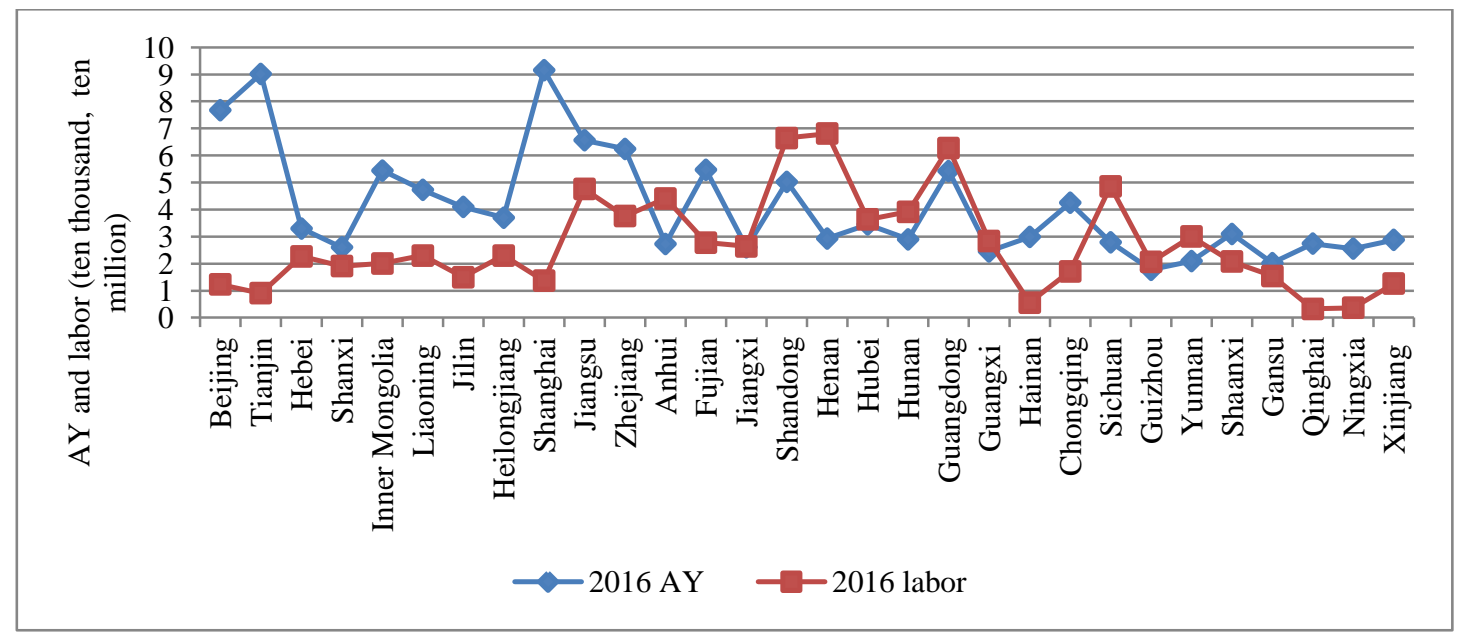

ISSN: 0010-8189 
Third, the logarithm of total factor productivity $(\mathrm{C})$ is positive, which indicates that the growth rate of total factor productivity (A) has a positive relationship with economic growth. Before 2009, the value of C remained stable in the fluctuation, and after 2009, the value of C showed a downward trend, which indicates that the effect of total factor productivity on economic growth was weakening.

\subsubsection{Output Elasticity of All Factors and the Pull Function on Economic Growth}

In equation (2), the value of $\mathrm{LnK}$ is the output elasticity coefficient $\alpha$ for physical capital, representing the degree of relative influence of physical capital on per capita GDP. A comparison of the coefficients $\alpha$ of each year shows that the coefficients increased rapidly from 2003 to 2004 and then increased slowly. The coefficients did not decrease until 2013, as shown in Figure 2. This shows that the positive impact of the growth rate of physical capital on the growth rate of per capita GDP was slowly increasing before 2013, and afterward the positive impact of the growth rate of physical capital on the growth rate of per capita GDP began to decline sharply.

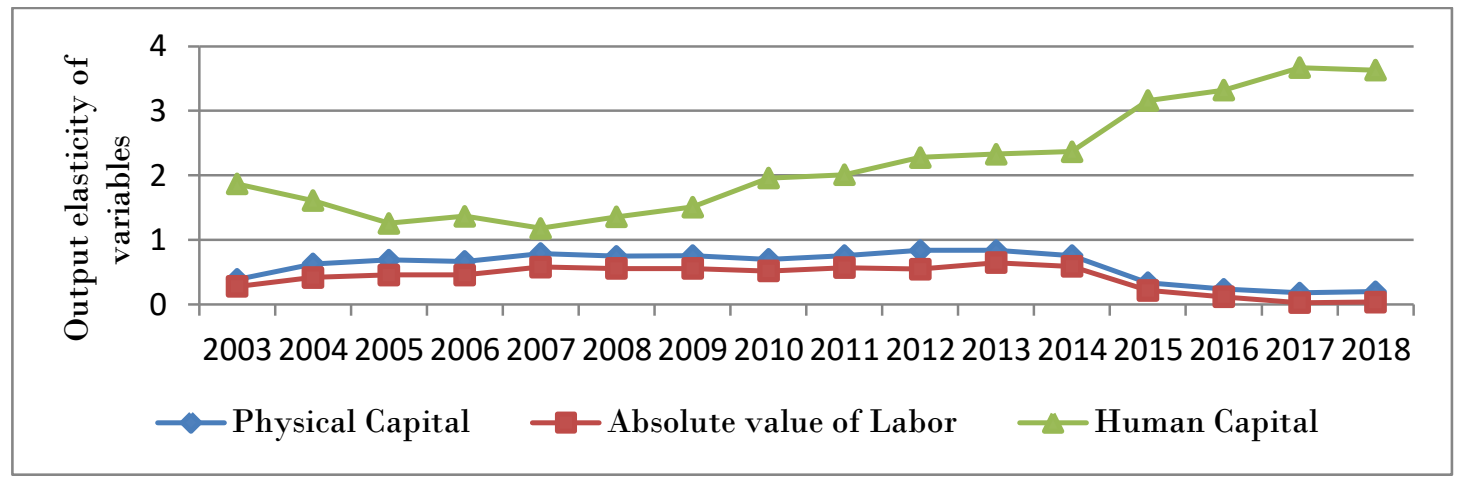

Fig 2: The effect degree of variables on AGDP from 2003 to 2018

The value of $\mathrm{LnL}$ is the output elasticity coefficient $\beta$ for labor, which represents the degree of influence of the growth rate of labor on the growth rate of per capita GDP. By comparing the absolute value of coefficient $\beta$ in each year, we observe that the coefficient $\beta$ increases slowly from 2003 to 2007, then remains stable from 2007 to 2012 , and rises slightly in 2013. However, after 2013, the absolute value of coefficient $\beta$ begins to decline sharply, as shown in Figure 1. This shows that the negative influence of the growth rate of labor on the growth rate of per capita GDP remained steady, with a slight rise before 2013, but after 2013, the influence of the growth rate of labor input on per capita GDP began to decline rapidly. The value of $\mathrm{LnH}$ is the output elasticity coefficient $\psi$ for human capital, representing the degree of influence of the growth rate of human capital on the growth rate of per capita GDP. The comparison of this coefficient value in each year shows: first, the value of this coefficient is greater than 1 , and the minimum value is 1.18 in 2007 , which indicates that the increase in the growth rate of human capital to a certain extent causes a substantial increase in the growth rate of per capita GDP; second, on the whole, the impact of the growth rate of human capital on the growth rate of per capita GDP is rising. The biggest impact occurs in 2017. For every $1 \%$ increase of human capital, per capita GDP increases by $3.67 \%$, as shown in Figure 1 . The sum of the output elasticity of three independent variables is greater than 1, which suggests that economic growth is in the stage of increasing returns to scale.

From 2003 to 2018, the coefficient of three independent variables K, L, and H, namely, the output elasticity of each factor, in order from large to small is: human capital, physical capital, and labor. The result suggests that each factor's effect on driving economic growth in China has changed since 2003. Human capital has become the primary driving factor behind economic growth. Physical capital is still the secondary driving factor behind economic growth. The effect of labor on economic growth is the smallest among all factors. Moreover, since 2014, the value of physical capital and the labor force has declined sharply, while the value of human capital in education has risen rapidly. The influence of physical capital and labor on per capita GDP has therefore declined, while the 
positive influence of human capital on promoting regional economic growth has been greater.

\subsubsection{Total Factor Productivity}

In equation (2), The constant term $\mathrm{C}$ is the growth rate of total factor productivity. The growth rate of total factor productivity has a positive relationship with economic growth from 2003 to 2018. This indicates that the efficiency of resource allocation has improved. However, the value of $\mathrm{C}$ is decreasing, which indicates that the speed of improvement in the efficiency of resource allocation is decreasing.

\section{Conclusion and Policy Recommendations}

The real economic growth of a country is affected by the demand factor in the short term, while in the long term it is affected by the supply factor, which is expressed in the economic theory as the potential economic growth rate. The potential economic growth rate is determined by two kinds of factors: the first is the growth rate of input of factors of production, and the second is the growth rate of total factor productivity. $\mathrm{T}$

The empirical results show that the determinants driving growth have changed. China is transforming from the post-Malthusian growth stage to the modern economic growth stage, in which demographic transition will play an important role. With the impact of labor on per capita GDP declining, the traditional demographic dividend has gradually disappeared in China, and its economic growth is undergoing a critical change from being driven by factors and investment to being driven by innovation. Innovation includes technological innovation, institutional innovation, and talent innovation, among which technological innovation is the core, institutional innovation is the guarantee, and talent innovation is the basis of innovation. Increasing investment in human capital and developing talent dividends have become a new driving force for sustained economic growth and an effective way to promote balanced and coordinated development of the regional economy.

Our findings have the following policy implications. Supply-side reform mainly includes improving human capital and total factor productivity in China. First, China should increase investment in human capital and focus on developing talent as the primary long-term strategy for carrying out economic transformation. To a large extent, human capital can be seen as the size of the ordinary labor force. Increasing human capital means increasing the labor supply, improving and increasing the potential growth rate with the labor input. Education is the most important way to invest in human capital. Hence, China should strengthen its education system, including vocational education, which will facilitate industrial upgrading. Over time, with the accumulation of human capital and the improvement in labor quality, labor productivity will increase. Only then will China realize the second "demographic transition," from a demographic dividend to talent bonuses. Then, the Chinese economy will also achieve a transformation from growth based on quantity to one based on quality.

Second, the growth rate of total factor productivity has a positive relationship with economic growth, but the growth rate of it is falling. When unlimited labor supply and population mobility are reduced, the main drivers of China's economic growth, the demographic dividend and total factor productivity, will weaken or even disappear, resulting in a rapid decline in the potential growth rate. But there are other sources of total factor productivity. In addition to the efficiency of resource allocation from population mobility, the main driving forces for increasing total factor productivity are technological progress and institutional improvement. In particular, when it becomes difficult to reverse the weakening of the "demographic dividend," an model of extensive economic growth driven by increased factor inputs will become unsustainable. Increasing total factor productivity will be the main driver of economic growth in future. Therefore, China should improve total factor productivity through institutional improvement and technological progress, so as to raise the potential growth rate. A series of reforms to improve the institutional environment are essential for China to enter a new phase of economic growth, and an incentive mechanism of technological innovation needs to be established.

Third, physical capital is still the secondary driving factor in economic growth. Therefore, China should continue to focus on the accumulation of physical capital and steady investment. As a developing country, where per capita

ISSN: 0010-8189 
GDP is only one-fifth that of developed countries, China still has strong effective demand and investment capacity in its domestic capital accumulation.

Fourth, the existence of a regional economic gap allows China some room for maneuver in its economic transformation. Low-end labor-intensive industries should be gradually transferred to western China as eastern and central China turn to industrial upgrading. Thus, on the one hand, central and western China can gain resources and power for accelerating development, while, on the other hand, eastern China can accelerate the pace of industrial transformation and upgrading, which will benefit regional gradient transformation and help permit a smooth transition.

Fifth, Chinese policy makers should pay attention to the gap in factor allocation in eastern, central, and western China and try to narrow the gap in economic development. To do so, the government should increase educational investment in western China to achieve educational equity. In addition, China should increase investment in social infrastructure in central and western China, which not only will promote growth in these regions and improve their development environment but also attract an inflow of talent.

\section{Acknowledgments}

This research is supported by National Social Science Fund of China (Grant No. 18XJY005).

\section{References}

[1] Galor, O. and Mountford, A. 2008. “Trading Population for Productivity: Theory and Evidence.” Review of Economic Studies 75, pp. 1143-1179.

[2] Galor, O., and Weil, D.N. 2000. "Population, Technology, and Growth: From Malthusian Stagnation to the Demographic Transition and Beyond." American Economic Review 90, pp. 806-828.

[3] Hansen, G., and Prescott, E. 2002. "From Malthusian to Solow.” American Economic Review 92, pp. 12051217.

[4] Jones, C.I. 2001. "Was an Industrial Revolution Inevitable? Economic Growth over the Very Long Run." Advances in Macroeconomics 1, no. 2, Article 1.

[5] Tamura, R. 2002. "Human Capital and the Switch from Agriculture to Industry." Journal of Economic Dynamics and Control 27, pp. 207-242.

[6] Lagerlof, N. 2003. "From Malthus to Modern Growth: Can Epidemics Explain the Three Regimes?" International Economic Review 44, pp. 755-77.

[7] Galor, O., and Moav, O. 2004. "From Physical to Human Capital Accumulation: Inequality and the Process of Development.” Review of Economic Studies 71, pp. 1001-1026.

[8]Doepke, M. 2004. "Accounting for Fertility Decline during the Transition to Growth.” Journal of Economic Growth 9, pp. 347-383.

[9] Boucekkine, R., et al. 2003. "Early Mortality Declines at the Dawn of Modern Growth." Scandinavian Journal of Economics 105, pp. 401-418.

[10] Galor, O. 2010. "Comparative Economic Development: Insights from Unified Growth Theory." International Economic Review 51, pp. 1-44. 